\title{
Using behavior as an early predictor of sickness in veal calves
}

\author{
M. A. Belaid, ${ }^{1}$ M. Rodríguez-Prado, ${ }^{1}$ D. V. Rodríguez-Prado, ${ }^{2}$ E. Chevaux,${ }^{3}$ and S. Calsamiglia ${ }^{1 *}$ \\ ${ }^{1}$ Animal Nutrition and Welfare Service, Department of Animal and Food Sciences, Universitat Autònoma de Barcelona, Bellaterra 08193, Spain \\ ${ }^{2}$ Universitat Pompeu Fabra, Barcelona 08002, Spain \\ ${ }^{3}$ Lallemand SAS, 31702 Blagnac, France
}

\begin{abstract}
The objective of this study was to analyze whether changes in behavior can be a good early predictor of sickness in calves. Friesian males calves ( $\mathrm{n}=325 ; 30$ $\pm 9 \mathrm{~d}$ of age; $65 \pm 15 \mathrm{~kg}$ ) were monitored with an activity-monitoring device from 30 to $90 \mathrm{~d}$ of life in 4 periods corresponding to 4 seasons. The activity-monitoring device measured number of steps, number of lying bouts, lying time, and frequency and time of visits to the feed bunk. Calf health status was monitored daily and all incidences were recorded. To compare sick and healthy calves, a matched pair design was used to assign calves into the healthy group. Day 0 was defined as the day of sickness diagnosis. For each sick calf, 3 calves with no signs of sickness during the entire period (healthy calves) on the same date, in the same season, and of similar age $( \pm 4 \mathrm{~d})$ and weight at entry were identified. A multivariate linear mixed model was used from $\mathrm{d}-10$ to +10 relative to the sickness diagnosis to describe differences between sick and healthy calves. A multivariate logistic regression model was used for predicting sick calves on the days before the diagnosis. Significance was declared at $P<0.05$. Daily, healthy calves had 1,476 \pm 195 steps, spent $185 \pm 32.5$ min at the feed bunk, consumed $10 \pm 1.1$ meals, had $19.5 \pm$ 1.8 lying bouts, and spent an average of $978 \pm 30.5 \mathrm{~min}$ lying. The difference in behavior between sick $(\mathrm{n}=33)$ and healthy calves $(\mathrm{n}=99)$ began to be evident on $\mathrm{d}$ -10 . Sick calves had fewer steps and numbers of visits to the feed bunk on $d-1$ and 0 and spent less time at the feed bunk on $\mathrm{d}-10$ and -1 compared with healthy calves. From d -2 to d 9, sick calves had 15\% fewer lying bouts, with no difference in lying time except on d -10 , when sick calves spent more time lying. The best prediction model was for $\mathrm{d}-1$ and included season and age at entry as qualifying variables, and frequency of visits to the feed bunk, steps, and lying time as behavior predictors (69\% sensitivity, $72 \%$ specificity,
\end{abstract}

Received May 1, 2019.

Accepted July 31, 2019.

*Corresponding author: Sergio.Calsamiglia@uab.cat
$72 \%$ accuracy, $55 \%$ false discovery rate, and $12 \%$ false omission rate). However, an earlier prediction would be more useful to reduce the negative effect of sickness on production and welfare. The prediction model for $\mathrm{d}$ -10 had $67 \%$ sensitivity, $67 \%$ specificity, $67 \%$ accuracy, $60 \%$ false discovery rate, and $14 \%$ false omission rate. Results indicate that the occurrence of sickness can be predicted in advance, and an automated alarm system could be used to identify calves at risk of becoming sick and apply a preventive treatment.

Key words: calf behavior, activity-monitoring system, sickness prediction

\section{INTRODUCTION}

Mortality and morbidity in calves represent an important cost for farmers and a significant welfare issue (Ortiz-Pelaez et al., 2008; Mohd Nor et al., 2012). Upon arrival at the farm, calves are often exposed to sickness challenges and experience stress resulting from commingling, transportation, new housing facilities, and adaptation to a new diet (Mormede et al., 1982; Van der Fels-Klerx et al., 2000). Prophylactic treatments, including antibiotics, are often used to prevent or treat respiratory or enteric infections (Quigley et al., 1997; Silbergeld et al., 2008). Currently, the use of antimicrobials in calves is high (Pardon et al., 2012) and is partly responsible for the development of microbial resistance to antibiotics (Silbergeld et al., 2008; Catry et al., 2016). The World Health Organization and the European Union recommend a reduction in the use of antibiotics for animal production (European Commission, 1998; Ferber, 2003). Moreover, there is pressure from the medical community and consumers to reduce antimicrobial use in animal agriculture, which provides an additional motivation to raise cattle without antibiotics. Therefore, it would be advantageous to encourage the development of management strategies to prevent or minimize sickness and reduce the use of antibiotics (Torrence, 2001) by targeting only calves at risk. Identifying morbid calves at an early stage may increase treatment effectiveness, promote a prompt recovery, and improve animal welfare (Schoening et al., 2005). 
However, the intensification of production systems decreases human-animal interactions, which further complicates the visual diagnosis of sicknesses (Frost et al., 1997; Berckmans, 2004).

Monitoring cattle behavior using automated devices, such as wearable accelerometers and automatic calf feeders, can be a good option for easy identification of animals at risk of sickness (Trénel et al., 2009). Quimby et al. (2001) reported that feeding behavior could also be useful to predict morbidity in calves $4 \mathrm{~d}$ before its diagnosis by farm personnel. Svensson and Jensen (2007) found that sick calves had fewer unrewarded visits to the feeder than healthy calves on the day that they were diagnosed sick by farm personnel. Borderas et al. (2009) also reported that calves fed a high milk allowance decreased their daily average milk intake when sick and were less active and had reduced lying times when diagnosed with respiratory sickness compared with healthy calves 1 to $2 \mathrm{~d}$ before having clinical symptoms. Another study reported that calves with neonatal calf diarrhea tended to have fewer unrewarded visits to automatic milk feeders, lower milk consumption, and fewer lying bouts than healthy calves (Sutherland et al., 2018). These previous studies focused predominantly on feeding behavior related to milk consumption. Feeding behavior corresponding to concentrate consumption has rarely been studied in milk-fed calves and after weaning. New activitymonitoring devices are being developed that measure and record activity, rumination, and number of visits and time at specific locations in the farm (Borchers et al., 2016).

We hypothesized that measuring activity and time and frequency of visits to the feed bunk would allow the early identification of calves at risk of becoming sick. The aim of this study was to determine whether activity-monitoring systems that measure daily activity and frequency and time of visits to the feed bunk could be used as an early predictor of risk of sickness in young calves.

\section{MATERIALS AND METHODS}

\section{Animals, Feeding, and Management}

The experiment was conducted from March 2017 to January 2018. A total of 325 veal calves originating from surrounding dairy farms were enrolled in the study and distributed in 4 groups of calves that arrived on the farm in March $(\mathrm{n}=85)$, June $(\mathrm{n}=85)$, September ( $\mathrm{n}$ $=80)$, and October $(\mathrm{n}=75)$. Friesian male veal calves $(\mathrm{n}=325,30 \pm 9 \mathrm{~d}$ of age at arrival, and $65 \pm 15 \mathrm{~kg}$ of BW) were monitored throughout the first $60 \mathrm{~d}$ after their arrival at the farm. On the day of arrival, calves were weighed with a digital scale (Agroterra, Valencia, Spain) and divided into 3 groups of $25 \pm 5$ calves based on BW. They received vaccines against infectious bovine rhinotracheitis (Hiprabovis, Hipra, Amer, Spain), bovine viral diarrhea virus (Bovela, Boehringer Ingelhem, Sant Cugat del Valles, Spain), and an external and internal antiparasitic treatment (ivermectin, Promectine, Proyma, Ciudad Real, Spain). Calves were housed in a straw-bedded, covered, open-side barn with natural ventilation and in pens that provided a space allowance of approximately $3 \mathrm{~m}^{2} /$ calf.

During the first 5 wk after arrival, calves were bottlefed with $2 \mathrm{~L}$ of milk replacer $(130 \mathrm{~g} / \mathrm{L} ; 22 \%$ protein, $19 \%$ fat; Denkavit, Lleida, Spain) twice daily at approximately 0700 and $1900 \mathrm{~h}$. Calves had ad libitum access to a texturized calf starter (16\% protein, $3.8 \%$ fat; Super's Diana, Parets del Valles, Spain), and grass hay provided ad libitum in a 20-m-long feed bunk along each pen. Water was provided through an automatic waterer. Orts of the dry food were removed daily from the feed bunk before new fresh dry food was provided. Calves were weaned after 5 wk and remained in their location for an additional $3 \mathrm{wk}$, where they had ad libitum access to dry concentrate, hay, and water.

\section{Data Collection}

When calves arrived at the facility, an activity-monitoring device previously validated for steers (Fedometer system, FEDO; ENGS, Rosh Pina, Israel; Wolfger et al., 2015) was fitted onto the front left leg at the level of the metacarpus. Calves were monitored throughout the whole period $(9 \pm 2 \mathrm{wk})$ and the FEDO was removed at the end of the experiment. The FEDO recorded activity (number of steps, number of lying bouts, and lying time) and duration and frequency of visits to the feed bunk. The feed bunk was equipped with an electromagnetic field-generating antenna that detects the proximity of animals to the feed bunk $(30 \pm 2 \mathrm{~cm}$ in front of the feed bunk) and, thus calculates the number of visits and duration at the feed bunk. Data were recorded continuously and transmitted wirelessly every $6 \mathrm{~min}$ to a computer with system-specific software (Eco-herd software; ENGS). The system was checked periodically for proper functioning. Calf identification, birth date, BW, and group entry date were recorded for each animal. At the end of each period, data were downloaded into an Excel spreadsheet (Microsoft Corp., Redmond, WA) and summarized by day.

Each calf was observed twice daily individually at feeding times by the same farm manager for signs of sickness. The standard operating procedures of the farm included a checklist of criteria used to identify sick calves. A calf was diagnosed as having respira- 
tory sickness when observed with crackly breath, rapid breathing, or coughing, or had ocular or nasal discharge; with digestive problems when they had diarrhea (feces with a loose to watery consistency, presence of loose fecal matter on the top of the tail or legs, strong odor, and dehydration); or with no specific diagnosis when depressed and with a rectal temperature $>39.5^{\circ} \mathrm{C}$. Calf diagnosis and treatment were done by the attending veterinarian within $12 \mathrm{~h}$ of the diagnosis, and treatments were applied for at least 3 consecutive days. Calves with respiratory disease were treated with antibiotics, and the remainder were treated with a combination of antibiotics and anti-inflammatories. The date of diagnosis and the time of each treatment were recorded for each morbidity event.

\section{Statistical Analyses}

All statistical analyses were performed with SAS (version 9.4; SAS Institute Inc., Cary, NC). Healthy calves were those that had no clinical signs during the whole experimental period. For the normal behavior of healthy calves, descriptive statistics were recorded for the entire period with all calves not diagnosed sick $(\mathrm{n}=290)$. A matched pair design was used to assign calves into the healthy group for the development of prediction models. Day 0 was defined as the day of sickness diagnosis. For each sick calf, we identified 3 healthy calves on the same date in the same season, of a similar age $( \pm 4 \mathrm{~d})$ and approximately the same BW at entry. Most previous reports have measured activity 4 to $5 \mathrm{~d}$ before the diagnosis but, in most cases, the difference in activity between healthy and sick calves was already apparent (Borderas et al., 2009; Swartz et al., 2017; Sutherland et al., 2018). Therefore, data analysis was conducted from $10 \mathrm{~d}$ before to $10 \mathrm{~d}$ after diagnosis and the first treatment. For sick calves that were treated multiple times, only the first treatment event was considered. Once the database was generated, a multivariate linear mixed model was built to describe differences in each behavioral index between sick and healthy calves. The model included calf health status (healthy or sick), season, age at entry, days around the diagnostic event from $\mathrm{d}-10$ to +10 , the interaction between days and health status as fixed effects, and the animal as a random effect. When an interaction was significant, the SLICE option was used to evaluate it.

To verify the usefulness of behavior indexes for predicting sick calves, a multivariate logistic regression model was used on the days before the treatment event to identify variables associated with health status. This model included the fixed effects of season (month of entry), age at entry, and all behavior indexes. All predictors with $P<0.20$ were initially included in the model. The backward stepwise procedure was used to eliminate variables from the regression model until all remaining predictors were significant. For each model, the sensitivity $(\mathbf{S e})$ and specificity $(\mathbf{S p})$ were calculated for each possible cut-off point, as described by Dohoo et al. (2003), and the cut-off point that yielded the highest combination of Se and Sp was selected. Diagnostic test characteristics included accuracy, false discovery rate (FDR), and false omission rate (FOR; Dohoo et al., 2003). The Se is defined as the probability that a positive alert is a true indicator of sick calves, and the Sp is the probability that a negative alert is a true indicator of healthy calves. The FDR was defined as the proportion of calves that were diagnosed incorrectly as being sick and expressed as a percent of sick calves. The FOR was defined as the proportion of calves that were diagnosed incorrectly as being healthy and expressed as percent of healthy calves. Accuracy was defined as the proportion of healthy and sick calves diagnosed correctly (Dohoo et al., 2009). Models with an area under the curve (AUC) $>0.70$ were chosen to construct the final prediction models.

\section{RESULTS}

In total, $33(10 \%)$ calves were diagnosed sick, of which $17(51 \%)$ were treated with antibiotics against bovine respiratory sickness and $16(49 \%)$ had no specific diagnosis and received a general treatment based on antibiotics and anti-inflammatories. Most calves became sick within the first 5 wk $(20 \pm 10 \mathrm{~d})$ after arrival at the receiving facility. Only 2 calves died within the first $2 \mathrm{wk}$, one with intestinal torsion and the other with serious lung injuries, representing a mortality rate of $0.61 \%$.

\section{Normal Behavior}

A total of 290 healthy calves were used to describe daily normal behavior during the experimental period (Figure 1). Over the entire period, on average (mean \pm SD), each day calves had 1,476 \pm 195.2 steps and visited the feed bunk $10.5 \pm 1.1$ times, where they spent $185 \pm$ $32.5 \mathrm{~min}$. They had $19.5 \pm 1.75$ lying bouts and spent, on average, $978 \pm 30.5$ min lying. Over the time of the trial, calves increased their daily steps and frequency and duration of visits to the feed bunk and lying bouts (Figure 1A, B, C, and D); lying time remained constant (Figure 1E).

\section{Sick Versus Healthy Calves}

The comparison between sick $(\mathrm{n}=33)$ and healthy $(\mathrm{n}=99)$ calves from $10 \mathrm{~d}$ before and after the first 
A

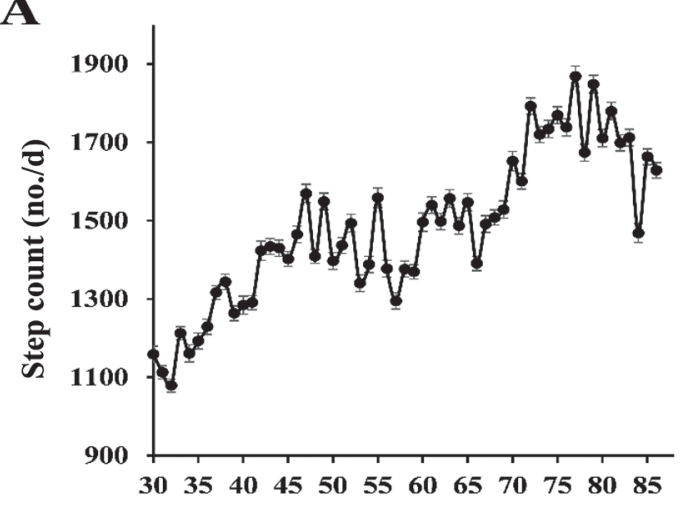

C

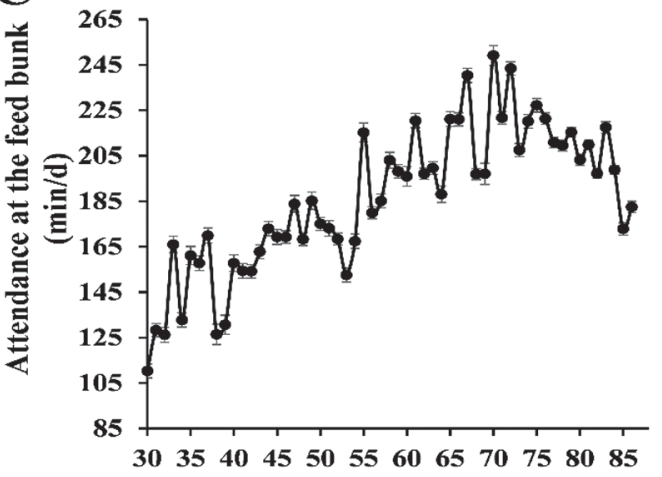

$\mathbf{E}$

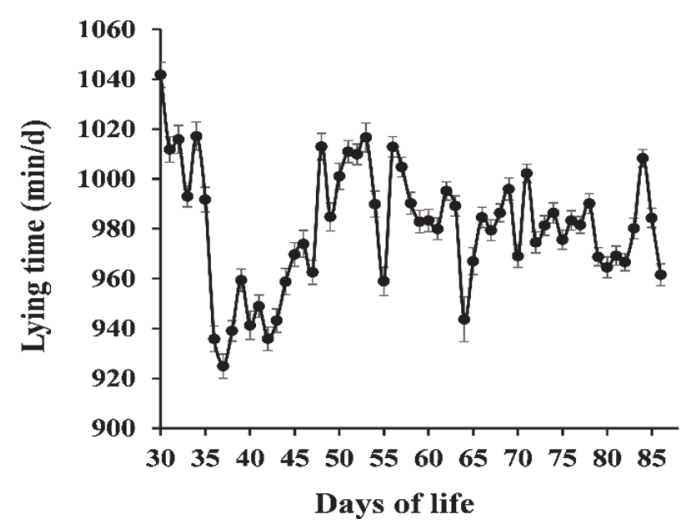

B

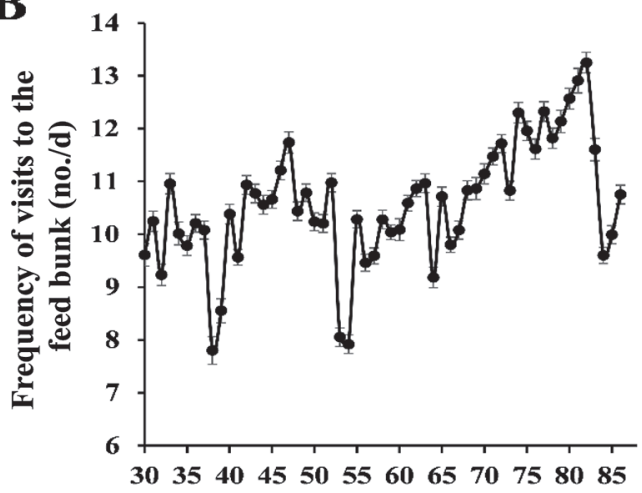

D

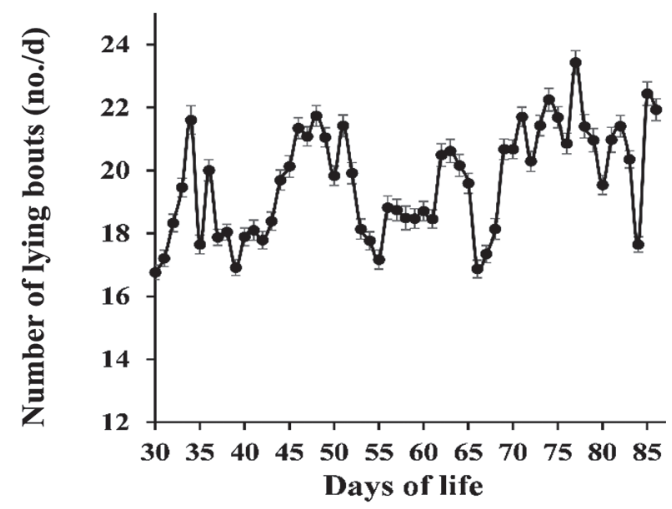

Figure 1. Daily step counts (A; no./d), frequency of visits to the feed bunk (B; no./d), duration of visits at the feed bunk (C; min/d), number of lying bouts (D; no./d), and lying time (E; min/d) in healthy calves from 30 to $90 \mathrm{~d}$ in life. Error bars indicate SEM.

treatment event (step counts, frequency and duration of visits to the feed bunk, lying bouts, and lying time) are presented in Figure 2. In general, sick calves were less active than healthy calves. The change in behavior was already evident on $d-10$. Step counts, frequency of visits to the feed bunk, and lying bouts were the most affected by health status. Table 1 shows $P$-values for the effect of health status, days of sickness, season, age, and the interaction between health status and days of sickness for all behavioral indexes. During the $20 \mathrm{~d}$ around the initial sickness diagnosis, sick calves had fewer steps than healthy calves $(1,164 \pm 75.6$ vs. 1,390 \pm 50.6 steps/d, respectively). From d -10 to $d+10$, the difference observed was either significant $(\mathrm{d}-10$, $-7,-5,-2,-1,0,1,2,3,4,5,6,7,8,9$, and 10) or tended to be significant ( $\mathrm{d}-6$ and -4 ). Sick calves also visited the feed bunk less, by almost $18 \%$, in the days preceding and the day before being diagnosed sick compared with healthy calves. Differences were either significant (d -10, $-9,-8,-6,-3,-2,-1$, and 0 ) or 
tended to be significant $(\mathrm{d}-7$ and -5$)$. After medical treatment, differences in the frequency of visits to the feed bunk decreased, being only a tendency on d 4 . Sick calves spent less time at the feed bunk than healthy calves on $\mathrm{d}-10(117 \pm 15.3$ vs. $160 \pm 9.8 \mathrm{~min} / \mathrm{d}$, respectively $)$ and on $\mathrm{d}-1(140 \pm 12.9$ vs. $180 \pm 8.7$ $\mathrm{min} / \mathrm{d}$, respectively). Differences in lying bouts were significant on d $3,4,5,6$, and 8 ; and tended to differ on $\mathrm{d}-2,-1,0,2,7$, and 9 , with sick calves having $15 \%$ fewer lying bouts than healthy calves. No difference in lying time was detected between sick and healthy calves, either before or after the sickness was diagnosed, except on $\mathrm{d}-10$, when sick calves spent more time lying than healthy calves $(1,077 \pm 21.3$ vs. $1,012 \pm 13.4$ $\min / d$, respectively).

\section{Prediction Models}

Outcomes of the diagnostic test characteristic resulting from all of the statistical models are summarized in Table 2. Prediction models with AUC $>0.70$ were found for $\mathrm{d}-10,-2$, and -1 . The best predictor model was found for $\mathrm{d}-1$ ( $\mathrm{Se}=69 \%$; $\mathrm{Sp}=72 \%)$. This model included season and age at entry as qualifying variables, and steps, lying time, and the frequency of visits to the feed bunk as remaining predictors from the stepwise process. Using the cut-off point chosen from the highest Se and Sp, the model had $72 \%$ accuracy, 55\% FDR, and $12 \%$ FOR. The prediction models for $\mathrm{d}-2$ and $\mathrm{d}$ -10 were similar, and both included season and age at entry as qualifying variables, and step count as the only remaining predictor from the stepwise process. The prediction model for $\mathrm{d}-10$ had $67 \%$ Se, $67 \%$ Sp, $67 \%$ accuracy, $60 \% \mathrm{FDR}$, and $14 \% \mathrm{FOR}$, and the prediction model for d -2 had $72 \%$ Se, $67 \%$ Sp, $68 \%$ accuracy, $58 \%$ FDR, and $12 \%$ FOR. Table 3 presents the result of the analysis of maximum likelihood estimates for the prediction models of $\mathrm{d}-10,-2$, and -1 .

\section{DISCUSSION}

The change in behavior of animals in response to sickness is well established (Hart, 1988) and includes reduced activity, decreased feed intake, and lethargy. This change in behavior serves as a survival strategy to direct most of the animal's energy to immune defense mechanisms, and the physiological reactions involved in the development of such changes have been well described (Dantzer and Kelley, 2007). We hypothesize that this change in behavior could be used to predict animals at risk of becoming sick well in advance of the development of clinical symptoms. Because limited data are available on the normal behavior of young calves limit-fed milk replacer in group housing systems, the discussion will address the behavior of healthy calves, the comparison of healthy and sick calves, and the usefulness of prediction models to identify calves at risk of becoming sick.

\section{Normal Behavior}

To our knowledge, no studies have specifically measured daily steps in calves of similar age as in the present study. Devant et al. (2012) reported that young bulls (age $=166 \pm 0.4 \mathrm{~d}$ ) had an average of 1,152 steps/d throughout a study, including the castration period, which was lower than the value observed in our study $(185 \pm 4.24)$. This lower activity was attributed to the effect of castration in response to pain. Surprisingly, the average number of steps in healthy adult cattle is similar to those reported for the calves herein (1,440 steps/d; Chapinal and Tucker, 2012). Most studies have focused on milk feeding behavior of calves, but only a few have measured feeding behavior in relation to consumption of concentrate in milk-fed calves. The average frequency of visits to the feed bunk reported in our study was similar to those reported for milk consumption visits, where the frequency of visits to the automatic milk-feeding machine in calves ranged from 4 to 10 meals per day (Senn et al., 2000; De Paula Vieira et al., 2010; Wojciech, 2013). However, the comparison is difficult because, in our trial, milk was fed restricted $(2 \times$ daily $)$, whereas in the other research used for comparison, milk was fed ad libitum. Jezierski (1987) reported that healthy calves at 30 to $60 \mathrm{~d}$ of age consumed concentrate feed on average during 150 $\mathrm{min} / \mathrm{d}$. Our results agree with their finding, because although the average in the current study was $180 \mathrm{~min} / \mathrm{d}$, calves were monitored from d 30 to 90 , but if calculated for d 30 to 60 , the average in our study was $161 \mathrm{~min} / \mathrm{d}$. The lying bouts were similar to those found by Sutherland et al. (2017). The lying time reported herein (16.8 $\mathrm{h} / \mathrm{d}$ ) was similar to that reported by Chmielnik et al. (1988; from 16 to $18 \mathrm{~h} / \mathrm{d})$, Chua et al. $(2002 ; 16.8 \mathrm{~h} / \mathrm{d})$, and Sutherland et al. (2017; from 16.8 to $17.3 \mathrm{~h} / \mathrm{d}$ ). The increase in these activities with age for most of the indexes should be taken into account when designing algorithms to predict the incidence of sickness at any age. Because the paired design used animals of the same age and BW, the model used in the present paper was adequate.

\section{Sick Versus Healthy Calves}

Most research on the use of step counts to predict sickness before clinical signs become visible has been conducted in adult dairy cows with lameness, but only a few studies have been conducted in calves. In our study, 

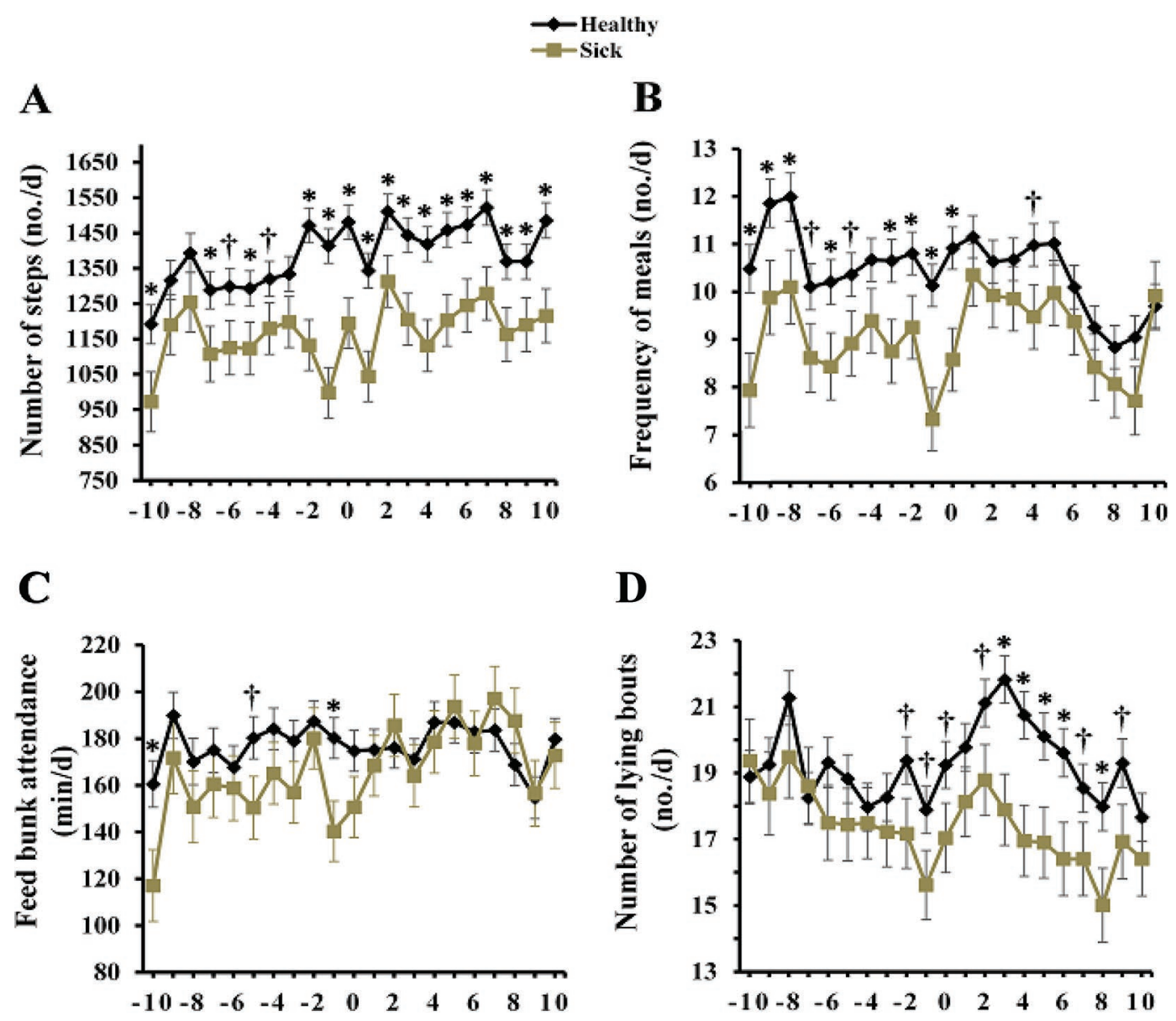

D

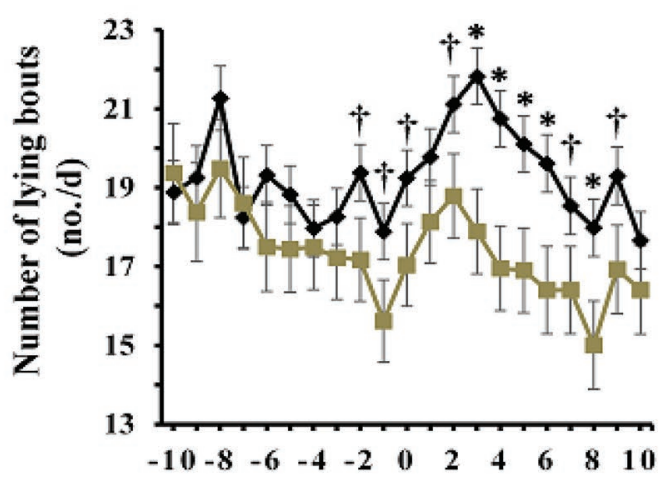

Days relative to treatment

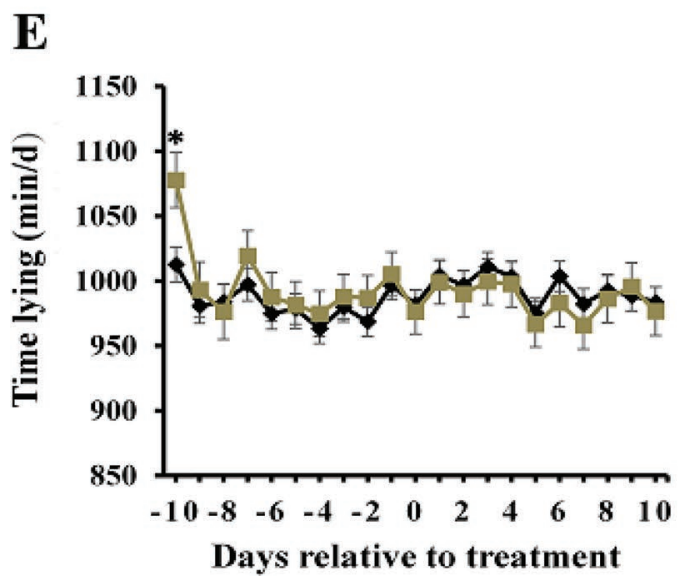

Figure 2. Daily step counts (A; no./d), frequency of visits to the feed bunk (B; no./d), duration of visits at the feed bunk (C; min/d), number of lying bouts $(\mathrm{D} ; \mathrm{no} . / \mathrm{d})$, and lying time $(\mathrm{E} ; \mathrm{min} / \mathrm{d})$ for matched pairs of sick bulls $(\mathrm{n}=33)$ vs. healthy bulls $(\mathrm{n}=99)$ from $10 \mathrm{~d}$ before to 10 $\mathrm{d}$ after the treatment event. The day of sickness diagnosis and initial treatment is $\mathrm{d} 0$. Means within day differ $(* P<0.05)$ or tended to differ $(\dagger 0.05<P<0.10)$. Error bars indicate SEM.

sick calves were less active than healthy calves, with an average reduction in step counts of $17 \%$. Swartz et al. (2017) reported that step activity in preweaning calves declined $1 \mathrm{~d}$ before clinical signs of respiratory sickness and remained low until $3 \mathrm{~d}$ after treatment. Marchesini et al. (2018) reported that activity and rumination in sick beef cattle during the fattening period $(367 \pm 67 \mathrm{~d}$ of age) were lower 3 to $6 \mathrm{~d}$ before the onset of clinical 
Table 1. The $P$-values for the effect of health status, days before sickness, season, and interaction between health status and days of sickness on the daily steps counts (no./d), frequency of visits to the feed bunk (no./d), duration of visits at the feed bunk (min/d), number of lying bouts (no./d), and lying time ( $\mathrm{min} / \mathrm{d})$ for matched pairs of sick calves (case; $\mathrm{n}=33$ ) versus healthy control calves $($ case; $\mathrm{n}=99)$

\begin{tabular}{|c|c|c|c|c|c|}
\hline Item & Step counts & $\begin{array}{l}\text { Frequency of visits } \\
\text { to the feed bunk }\end{array}$ & $\begin{array}{l}\text { Attendance to } \\
\text { feed bunk }\end{array}$ & Lying bouts & Lying time \\
\hline Season & $<0.05$ & $<0.05$ & $<0.05$ & $<0.05$ & $<0.05$ \\
\hline Age & $<0.05$ & 0.1 & $<0.05$ & 0.1 & 0.9 \\
\hline Health status & $<0.05$ & $<0.05$ & 0.3 & $<0.05$ & 0.8 \\
\hline Days $\times$ health & $<0.05$ & $<0.1$ & $<0.05$ & $<0.1$ & 0.6 \\
\hline
\end{tabular}

signs of sickness. Fröhner et al. (2011) reported that locomotion activity was lower in milk-fed sick calves, suggesting that this reduction could be used as an early prediction of sickness. Our results generally agree with these previous findings. A reduction in activity serves a survival strategy to devote most energy to the immune defense mechanisms (Hart, 1988; Dantzer and Kelley, 2007).

Sick calves performed $15 \%$ fewer lying bouts $2 \mathrm{~d}$ before the onset of the sickness diagnosis compared with healthy calves, and this difference persisted until $9 \mathrm{~d}$ after treatment. Similar to our findings, Swartz et al. (2017) observed that preweaning calves diagnosed with respiratory sickness began to decrease their lying bouts $2 \mathrm{~d}$ before having any symptom of sickness, and continued until 3 d after treatment. Sutherland et al. (2018) also reported that sick calves tended to have fewer lying bouts $5 \mathrm{~d}$ before having clinical signs of neonatal calf diarrhea. However, we observed no difference in lying time between sick and healthy calves except on $\mathrm{d}-10$, when sick calves spent more time lying than healthy calves. In general terms, most research reported no or only small effects of calves' health status on lying time (Swartz et al., 2017). Therefore, there seems to be general agreement that sick calves spend the same time lying but with fewer lying bouts.

Previous studies have predominantly focused on how milk feeding behavior is affected by sickness. To our knowledge, only 2 studies have addressed the effect of sickness on concentrate consumption behavior. Basarab et al. (1996) reported that feeding behavior and total time at the feed bunk were reduced when calves were sick, suggesting that monitoring feeding behavior could be a good method to detect sick calves instead of visual observation. Quimby et al. (2001) also studied behavior of concentrate feeding in newly received calves and reported that it could be used as a criterion to detect morbid animals $4 \mathrm{~d}$ before the diagnosis of the disease. The failure to see any change in feeding behavior in sick calves earlier than $4 \mathrm{~d}$ before the sickness diagnosis in this earlier study may be related to the fact that calves had restricted access to concentrate. Studies reporting feeding behavior of milk consumption had similar results. Calf had fewer visits and consumed less milk than healthy calves 1 to $4 \mathrm{~d}$ before the diagnosis (Borderas et al., 2009; Sutherland et al., 2018). The same results were found by Swartz et al. (2017), studying sick calves with respiratory sickness, where sick calves

Table 2. Outcomes of diagnostic test characteristics resulting from final prediction models from days before the diagnosis of a sick calf

\begin{tabular}{|c|c|c|c|c|c|c|}
\hline \multirow[b]{2}{*}{ Day $^{1}$} & \multicolumn{6}{|c|}{ Test characteristic ${ }^{2}$} \\
\hline & $\mathrm{AUC}$ & Accuracy $(\%)$ & Se $(\%)$ & $\mathrm{Sp}(\%)$ & FDR $(\%)$ & FOR $(\%)$ \\
\hline-10 & 0.74 & 66.7 & 66.7 & 66.7 & 60.0 & 14.3 \\
\hline-9 & 0.69 & 65.3 & 72.2 & 63.0 & 60.6 & 12.8 \\
\hline-8 & 0.67 & 59.7 & 66.7 & 57.4 & 65.7 & 16.2 \\
\hline-7 & 0.66 & 65.2 & 60.9 & 66.7 & 62.2 & 16.4 \\
\hline-6 & 0.68 & 63.0 & 72.0 & 60.0 & 62.5 & 13.5 \\
\hline-5 & 0.68 & 64.3 & 60.7 & 65.5 & 63.0 & 16.7 \\
\hline-4 & 0.60 & 53.3 & 63.3 & 50.0 & 70.3 & 19.6 \\
\hline-3 & 0.67 & 61.8 & 63.3 & 61.3 & 65.5 & 16.2 \\
\hline-2 & 0.73 & 68.0 & 71.9 & 66.7 & 58.2 & 12.3 \\
\hline-1 & 0.81 & 71.5 & 68.8 & 72.4 & 55.1 & 12.3 \\
\hline
\end{tabular}

${ }^{1}$ Day relative to the sick calf diagnosis.

${ }^{2} \mathrm{AUC}=$ area under the curve; $\mathrm{Se}=$ sensitivity; $\mathrm{Sp}=$ specificity $\mathrm{FDR}=$ false discovery rate $;$ and $\mathrm{FOR}=$ false omission rate. 
Table 3. The analysis of maximum likelihood estimates for the prediction models on $\mathrm{d}-10,-2$, and -1

\begin{tabular}{lccc}
\hline Parameter & Estimate & SEM & $P$-value \\
\hline Day -10 & & & \\
Intercept & 0.3320 & 1.7708 & $>0.10$ \\
Season & 0.1826 & 0.3760 & $>0.10$ \\
Age at entry & 0.0254 & 0.0420 & $>0.10$ \\
Step counts & -0.0023 & 0.0009 & $<0.05$ \\
Day -2 & 1.0446 & 1.2751 & $>0.10$ \\
Intercept & 0.2313 & 0.2628 & $>0.10$ \\
Season & 0.0202 & 0.0269 & $>0.10$ \\
Age & -0.0026 & 0.00066 & $<0.05$ \\
Step counts & & & $<0.05$ \\
Day -1 & 11.1638 & 3.9319 & $>0.10$ \\
Intercept & 0.2298 & 0.3013 & $>0.10$ \\
Season & 0.0389 & 0.0310 & $<0.05$ \\
Age & -0.0023 & 0.0007 & $<0.05$ \\
Step counts & -0.3836 & 0.1242 & $<0.05$ \\
Frequency of visits to the feed bunk & -0.0079 & 0.0030 & \\
Lying time & & & \\
\hline
\end{tabular}

consumed less milk than healthy calves on the day of sickness. Knauer et al. (2017) reported that preweaning sick calves $10 \mathrm{~d}$ before the sickness diagnosis had fewer visits than healthy calves, and this difference persisted until $10 \mathrm{~d}$ after treatment. Our results support those suggesting that feeding behavior could be a good early predictor of health disorders in calves. However, our observations indicate that calves at risk of becoming sick could be identified $10 \mathrm{~d}$ before the diagnosis compared with up to $5 \mathrm{~d}$ in the earlier studies. This discrepancy is likely related to the number of days before the sickness diagnosis that calves were monitored compared with previous studies $(<5 \mathrm{~d}$ in most cases; Borderas et al., 2009; Swartz et al., 2017; Sutherland et al., 2018), whereas we analyzed data from d -10 . In fact, because most previous research monitored behavior for 4 to $5 \mathrm{~d}$ before the diagnosis of the sick calf, we decided to extend the observation time $10 \mathrm{~d}$ before the diagnosis. However, differences in the number of steps and frequency and time at the feed bunk were already different from those of healthy animals at $d-10$ (Figure 2), suggesting that the observation time should be extended further.

\section{Prediction Models}

We examined whether it would be possible to identify sick calves before symptoms of sickness appeared through prediction models based on behavior indexes. The early detection of sick calves would allow the timely administration of proper treatment to only calves at risk, leading to a faster recovery, reduced production losses, and reduced use of antibiotics (Thompson et al., 2006; Duff and Galyean, 2007). It is worth mentioning that the diagnosis based on observation criteria was consistent with the day of a large and multi-criteria change in behavior, including reductions in the number of steps and lying bouts and in the number of visits and time at the feed bunk (Figure 2). The best prediction models were found for $\mathrm{d}-10,-2$, and -1 . Although the prediction model on $\mathrm{d}-1$ had the highest AUC, prediction on $\mathrm{d}-10$ (with AUC of $74 \%$ ) may be a better option because this would allow enough time to take advantage of early treatment. The application of the prediction model at $\mathrm{d}-10$ resulted in $67 \%$ accuracy, $67 \%$ Se, $67 \%$ Sp, $60 \%$ FDR, and $14 \%$ FOR. This FDR means that $60 \%$ of calves diagnosed as being sick by the prediction model would receive treatment unnecessarily. However, the system may alert farm staff to check animals as they may be at risk of becoming sick and need individual attention. Also, the system will allow identification of a large group of calves at no risk of becoming sick and, therefore, relieved from any preventive treatment. In contrast, the FOR would result in $14 \%$ of calves being undiagnosed; therefore, periodic surveillance of all animals would still be needed to catch sick calves not identified by the system. These predictions at $\mathrm{d}-10$ were obtained using only step counts as the variable, suggesting that many simple pedometers measuring only activity may be suitable and cheaper options for young calves. More research in this field is required to investigate whether other behavior indexes may improve the accuracy of predictions.

To our knowledge, very few studies have determined the effectiveness of automated devices to detect sick calves before clinical symptoms of disease. Most studies have predicted sickness by comparing behavior with baseline values of the same animal before becoming sick (Quimby et al., 2001; Cornou et al., 2008; Marchesini et al., 2018; Knauer et al., 2018). Marchesini et al. (2018) used a $9 \%$ reduction in rumination as criterion for the early detection of bovine respiratory sickness in calves 
$6 \mathrm{~d}$ before treatment and reported a higher Se (81\%) and Sp (95\%). However, the method requires at least $9 \mathrm{~d}$ before the onset of clinical sickness to establish the normal behavior of healthy calves in order to recognize changes caused by sickness. This lag time can affect the ability of the method to detect sick calves at arrival, where a high incidence of sickness is common. In contrast, the matched pair method we used could predict sick calves from the beginning without the need to establish a baseline normal behavior in each animal. Furthermore, detecting sickness based on a comparison of what happens today compared with yesterday can have a dramatic effect due to autocorrelation between days. If the changes in daily average of behavioral measures in individual calves from healthy day to a sick day are not large enough to activate a health alarm, the prediction will fail to identify sick calves and lead to a high FOR (Hawkins and Olwell, 1998). Knauer et al. (2018) used feeding behavior with this methodology to predict sick calves and reported that the feeding behavior of preweaning calves did not yield sufficient Se $(74.9 \%)$ and $\mathrm{Sp}(27.1 \%)$. The comparison of our results with those previous studies is difficult for many reasons, primarily the analytical method. In our study, sick calves were compared with healthy calves using the matched pair method, whereas, in most other studies, sick calves were compared with their own baseline behavior. Moreover, the age of calves among studies were different, making comparisons more difficult because behavior changes with age.

\section{CONCLUSIONS}

Sick calves modified their behavior by reducing the number of steps and lying bouts and the frequency and duration of visits at the feed bunk. Our prediction model was able to identify a sick calf at least $10 \mathrm{~d}$ before it was diagnosed by farm personnel. However, under the conditions of this methodology, the false discovery and omission rates were relatively high, and the model may require further refinement to improve the accuracy and precision of the method.

\section{ACKNOWLEDGMENTS}

This project was funded by the Ministerio de Economía y Competitividad. Gobierno de España; Project AGL2015-67409), Lallemand SAS (Blagnac, France), and ENGS Systems (Rosh Pina, Israel).

\section{REFERENCES}

Basarab, J. A., D. Milligan, R. Hand, and C. Huisman. 1996. Automatic monitoring of watering behavior in feedlot steers: Poten- tial use in early detection of respiratory disease and in predicting growth performance. Page 28 in Proc. Can. Soc. Anim. Sci. 46th Annu. Conf., Lethbridge, Alberta.

Berckmans, D. 2004. Automatic on-line monitoring of animals by precision livestock farming. Page 27-31 in Proc. the ISAH Conference on Animal Production in Europe: The Way Forward in a Changing World, Saint-Malo France. International Society for Animal Hygiene. https://www.isah-soc.org/userfiles/downloads/ symposiums/2004/isah2004.pdf.

Borchers, M. R., Y. M. Chang, I. C. Tsai, B. A. Wadsworth, and J. M. Bewley. 2016. A validation of technologies monitoring dairy cow feeding, ruminating, and lying behaviors. J. Dairy Sci. 99:74587466. https://doi.org/10.3168/jds.2015-10843.

Borderas, T. F., A. M. de Passillé, and J. Rushen. 2009. Feeding behavior of calves fed small or large amounts of milk. J. Dairy Sci. 92:2843-2852. https://doi.org/10.3168/jds.2008-1886.

Catry, B., J. Dewulf, D. Maes, B. Pardon, B. Callens, M. Vanrobaeys, G. Opsomer, A. de Kruif, and F. Haesebrouck. 2016. Effect of antimicrobial consumption and production type on antibacterial resistance in the bovine respiratory and digestive tract. PLoS One 11:e0146488. https://doi.org/10.1371/journal.pone.0146488.

Chapinal, N., and C. B. Tucker. 2012. Validation of an automated method to count steps while cows stand on a weighing platform and its application as a measure to detect lameness. J. Dairy Sci. 95:6523-6528. https://doi.org/10.3168/jds.2012-5742.

Chmielnik, H., D. Winnicka, and M. Jaworski. 1988. Dalsze badania nad przydatnością różnych typów smoków w odchowie cieląt. Zeszyty Problemowe Postępów Nauk Rolniczych. 333:127-132.

Chua, B., E. Coenen, J. van Delen, and D. M. Weary. 2002. Effects of pair versus individual housing on the behavior and performance of dairy calves. J. Dairy Sci. 85:360-364. https://doi.org/10.3168/jds .S0022-0302(02)74082-4.

Cornou, C., J. Vinther, and A. R. Kristensen. 2008. Automatic detection of oestrus and health disorders using data from electronic sow feeders. Livest. Sci. 118:262-271. https://doi.org/10.1016/j.livsci 2008.02.004.

Dantzer, R., and K.W. Kelley., 2007. Twenty years of research on cytokine-induced sickness behavior. Brain Behav. Immun. 21:153-160. https://doi.org/10.1016/j.bbi.2006.09.006.

De Paula Vieira, A., M. A. G. von Keyserlingk, and D. M. Weary. 2010. Effects of pair versus single housing on performance and behavior of dairy calves before and after weaning from milk. J. Dairy Sci. 93:3079-3085. https://doi.org/10.3168/jds.2009-2516.

Devant, M., S. Marti, and A. Bach. 2012. Effects of castration on eating pattern and physical activity of Holstein bulls fed highconcentrate rations under commercial condition. J. Anim. Sci. 90:4505-4513. https://doi.org/10.2527/jas.2011-4929.

Dohoo, I., W. Martin, and H. Stryhn. 2003. Screening diagnostic tests. Pages 85-113 in Veterinary Epidemiologic Research. AVC Inc., Charlottetown, PEI, Canada.

Dohoo, I., W. Martin, and H. Stryhn. 2009. Veterinary Epidemiologic Research. VER Inc., Charlottetown, Prince Edward Island, Canada.

Duff, G. C., and M. L. Galyean. 2007. Board-invited review: recent advances in management of highly stressed, newly received feedlot cattle. J. Anim. Sci. 85:823-840. https://doi.org/10.2527/jas.2006 $-501$.

European Commission. 1998. Council Regulation (EC) No 2821/98 of 17 December 1998 amending, as regards the withdrawal of the authorization of certain antibiotics, Directive 70/524/EEC concerning additives in feeding stuffs. Off. J. L351:4-8.

Ferber, D. 2003. Antibiotic resistance. WHO advises kicking the livestock antibiotic habit. Science 301:1027. https://doi.org/10.1126/ science.301.5636.1027.

Fröhner, A., A. Höldrich, K. Reitar, and H. Bernhardt. 2011. Early recognition of calve diseases with the help of electronic pedometer. Landtechnik 66:448-452.

Fröhner, A., A. Koßmann, and K. Reiter. 2008. Untersuchungen zum Verhalten und zur Vitalität bei Kälbern in den Haltungsverfahren ReinRaus und kontinuierliche Belegung. 40. Internationale Arbeit- 
stagung Angewandte Ethologie bei Nutztieren vom 20.-22.11.2008 in Freiburg/ Breisgau, KTBL-Schrift 471, Darmstadt, S. 220-222.

Frost, A. R., C. P. Schofield, S. A. Beaulah, T. T. Mottram, J. A. Lines, and C. M. Wathes. 1997. A review of livestock monitoring and the need for integrated systems. Comput. Electron. Agric. 17:139-159. https://doi.org/10.1016/S0168-1699(96)01301-4.

Hart, B. L. 1988. Biological basis of the behavior of sick animals. Neurosci. Biobehav. Rev. 12:123-137. https://doi.org/10.1016/S0149 $-7634(88) 80004-6$.

Hawkins, D. M., and D. H. Olwell. 1998. Cumulative Sum Charts and Charting for Quality Improvement. Springer-Verlag. New York.

Jezierski, T. A. 1987. Zachowanie się bydła o różnej użytkowości zależnie od genotupu I sposobu utrzymania [Behaviour of cattle of different utility traits depending on genotype and manage-ment]. Prace Habilitacyjne, Polska Akadema Nauk, Instytut Genetyki i Hodowli Zwierząt. [in Polish].

Knauer, W. A., S. M. Godden, A. Dietrich, and R. E. James. 2017. The association between daily average feeding behaviors and morbidity in automatically fed group-housed preweaned dairy calves. J. Dairy Sci. 100:5642-5652. https://doi.org/10.3168/jds.2016-12372.

Knauer, W. A., S. M. Godden, A. Dietrich, and R. E. James. 2018. Evaluation of applying statistical process control techniques to daily average feeding behaviors to detect disease in automatically fed group-housed preweaned dairy calves. J. Dairy Sci. 101:81358145. https://doi.org/10.3168/jds.2017-13947.

Marchesini, G., D. Mottarana, B. Contiero, E. Schiavon, S. Segato, E. Garbin, S. Tenti, and I. Andrighetto. 2018. Use of rumination and activity data as health status and performance indicators in beef cattle during the early fattening period. Vet. J. 231:41-47. https:/ /doi.org/10.1016/j.tvjl.2017.11.013.

Mohd Nor, N., W. Steeneveld, M. C. Mourits, and H. Hogeveen. 2012. Estimating the costs of rearing young dairy cattle in the Netherlands using a simulation model that accounts for uncertainty related to diseases. Prev. Vet. Med. 106:214-224. https://doi.org/ 10.1016/j.prevetmed.2012.03.004.

Mormede, P., J. Soissons, R. M. Bluthe, J. Raoult, G. Legarff, D. Levieux, and H. Dantzer. 1982. Effect of transportation on blood serum composition, disease incidence and production traits in young calves. Ann. Rech. Vet. 13:369-384

Ortiz-Pelaez, A., D. G. Pritchard, D. U. Pfeiffer, E. Jones, P. Honeyman, and J. J. Mawdsley. 2008. Calf mortality as a welfare indicator on British cattle farms. Vet. J. 176:177-181. https://doi.org/ 10.1016/j.tvjl.2007.02.006.

Pardon, B., C. Boudewijin, J. Dewulf, D. Persoons, M. Hostens, K. D. Bleecker, and P. Deprez. 2012. Prospective study on quantitative and qualitative antimicrobial and anti-inflammatory drug use in white veal calves. J. Antimicrob. Chemother. 67:1027-1038. https: //doi.org/10.1093/jac/dkr570.

Quigley, J. D., J. J. Drewry, L. M. Murray, and S. J. Ivey. 1997. Body weight gain, feed efficiency, and fecal scores of dairy calves in response to galactosyl-lactose or antibiotics in milk replacers. J. Dairy Sci. 80:1751-1754. https://doi.org/10.3168/jds.S0022 -0302(97) 76108-3.

Quimby, W. F., F. Sowell, J. G. P. Bowman, M. E. Branine, M. E. Hubbert, and H. W. Sherwood. 2001. Application of feeding be- haviour to predict morbidity of newly received calves in a commercial feedlot. Can. J. Anim. Sci. 81:315-320. https://doi.org/ 10.4141/A00-098.

Schoening, T. E., J. Wagner, and M. Arvand. 2005. Prevalence of erythromycin and clindamycin resistance among Streptococcus agalactiae isolates in Germany. Clin. Microbiol. Infect. 11:579-582. https://doi.org/10.1099/j.1469-0691.2005.01180.x.

Senn, M., S. Gross-Lüem, H. Leuenberger, and W. Langhans. 2000. Meal patterns and meal-induced metabolic changes in calves fed milk ad lib. Physiol. Behav. 70:189-195. https://doi.org/10.1016/ s0031-9384(00)00253-5.

Silbergeld, E. K., J. Graham, and B. L. Price. 2008. Industrial food animal production, antimicrobial resistance, and human health. Annu. Rev. Public Health 29:151-169. https://doi.org/10.1146/ annurev.publhealth.29.020907.090904.

Sutherland, M. A., G. L. Lowe, F. J. Huddart, J. R. Waas, and M. Stewart. 2018. Measurement of dairy calf behavior prior to onset of clinical disease and in response to disbudding using automated calf feeders and accelerometers. J. Dairy Sci. 101:8208-8216. https: //doi.org/10.3168/jds.2017-14207.

Sutherland, M. A., G. M. Worth, C. Cameron, C. M. Ross, and D. Rapp. 2017. Health, physiology, and behavior of dairy calves reared on 4 different substrates. J. Dairy Sci. 100:2148-2156. https://doi .org/10.3168/jds.2016-12074.

Svensson, C., and M. B. Jensen. 2007. Short communication: Identification of diseased calves by use of data from automatic milk feeders. J. Dairy Sci. 90:994-997. https://doi.org/10.3168/jds.S0022 -0302(07)71584-9.

Swartz, T. H., A. N. Findlay, and C. S. Petersson-Wolfe. 2017. Automated detection of behavioral changes from respiratory disease in pre-weaned calves. J. Dairy Sci. 100:9273-9278. https://doi.org/10 .3168/jds.2016-12280.

Thompson, P. N., A. Stone, and W. A. Schultheiss. 2006. Use of treatment records and lung lesion scoring to estimate the effect of respiratory disease on growth during early and late finishing periods in South Africa feedlot cattle. J. Anim. Sci. 84:488-498. https:// doi.org/10.2527/2006.842488x.

Torrence, M. E. 2001. Activities to address antimicrobial resistance in the United States. Prev. Vet. Med. 51:37-49. https://doi.org/10 $.1089 /$ fpd.2006.0066.

Trénel, P., M. B. Jensen, E. L. Decker, and F. Skjøth. 2009. Technical note: Quantifying and characterizing behavior in dairy calves using the Ice Tag automatic recording device. J. Dairy Sci. 92:33973401. https://doi.org/10.3168/jds.2009-2040.

Van der Fels-Klerx, H. J., H. S. Horst, and A. A. Dikkhuizen. 2000. Risk factors for bovine respiratory disease in dairy youngstock in The Netherlands: the perception of experts. Livest. Prod. Sci. 66:35-46.

Wojciech, N. 2013. Behaviour of calves in the first weeks of life. J. Cent. Eur. Agric. 14:33-41. https://doi.org/10.5513/JCEA01/14 .1.1151.

Wolfger, B., A. V. Mang, N. Cook, K. Orsel, and E. Timsit. 2015. Evaluation of a system for monitoring individual feeding behavior and activity in beef cattle. J. Anim. Sci. 93:4110-4114. https://doi .org/10.2527/jas.2015-8947. 